\title{
O tempo da escola: organização, ampliação e qualificação do tempo do ensino escolar
}

\section{Resumo}

Antonio Chizzotti

Roberta Maria Bueno Bocchi

Pontifícia Universidade Católica de São Paulo

Este artigo analisa a organização administrativa e pedagógica do tempo escolar e avalia as discussões sobre a ampliação da jornada escolar e a qualificação desse tempo dispendido no ensino com a finalidade de criar melhores condições de aprendizagem e de bem-estar para todos os que estão comprometidos com a vida da escola. $\bigcirc$ texto levanta algumas controvérsias e iniciativas internacionais, que buscam encontrar alternativas para promover uma disposição mais adequada desse ritmo do tempo a fim de propiciar melhores condições do sucesso no ensino e de qualidade na duração da jornada escolar. $\bigcirc$ entendimento metodológico deste trabalho de conformidade com Gaussel (2013) pressupõe o reconhecimento de uma pluralidade de tempos educativos e múltiplos modos legítimos de aprendizagem e ensino. Toma-se o calendário como modelo de organização e gerenciamento das atividades escolares, e de observações e contatos pessoais com os atores educacionais em uma escola, para levantar algumas considerações críticas sobre a disposição do ritmo do tempo escolar a partir da análise do calendário de uma escola pública do Ensino Médio do sistema de ensino do Estado de São Paulo.

Palavras-chave: Tempo escolar. Calendário escolar. Escola pública. Ensino médio.

\section{School Time: organization, expansion and qualification of school education time}

\section{Abstract}

This paper analyzes the administrative and pedagogical organization of school time and assesses the discussions on the extension of the school day and the qualification of time spent in teaching in order to create better conditions for learning and well-being of all who are committed to school. The text raises some controversy and international initiatives that seek to find alternatives to promote a more adequate provision of that time in order to provide better conditions for success in teaching quality and the duration of the school day. The methodological understanding of this work in accordance with Gaussel (2013) requires the recognition of a plurality of educational time and multiple legitimate ways of learning and teaching. It takes the calendar as model of organization and management of school activities and raises some critical observations on the disposition of school time from the analysis of the calendar of a public high school of São Paulo State education system.

Keywords: School Time. School calendar. Public school. High school. 


\section{El tiempo de la escuela: organización, ampliación y calificación del tempo la enseñanza escolar}

\section{Resumen}

Este artículo examina la organización administrativa y pedagógica del tiempo escolar y evalúa las discusiones sobre la ampliación de la jornada escolar y la calificación de ese tiempo dispendido em la enseñanza con la finalidade de crear mejores condiciones de aprendizaje y bien estar para todos los que están comprometidos con la vida de la escuela. El texto levanta algunas controversias y las iniciativas internacionales, que tratan de encontrar alternativas para promover una disposición más adecuada de ese ritmo del tiempo a fin de proporcionar mejores condiciones para el éxito en la calidad de la enseñanza y la duración de la jornada escolar. La comprensión metodológica de este trabajo de acuerdo con Gaussel (2013) requiere el reconocimiento de una pluralidad de tiempo educativo y múltiples formas legítimas de aprendizaje y enseñanza. Toma el calendario como un modelo de organización y gestión de las actividades actividades escolares, y las observaciones y los contactos personales persona con los agentes educativos en una escuela, para hacer algunas consideraciones críticas sobre la disposición del ritmo del tiempo de la escuela a partir

66 educación de estado de São Paulo.

Palabras clave: Tiempo escolar. Calendario escolar. Escuela pública. Enseñanza media.

\section{Introdução}

Este artigo propõe uma discussão sobre o tempo escolar - a duração, o ritmo, a divisão, a qualidade, a fruição do tempo - com o objetivo de refletir sobre a possibilidade de uma dinâmica mais significativa para a vida de todos aqueles que vivem na escola. Os esforços para qualificar a vida escolar despertaram o interesse em fazer um levantamento bibliográfico dos principais problemas vividos no recinto de uma escola do sistema de ensino.

A bibliografia levantada foi reunida e confrontada com uma convivência longa com esses problemas no contato com a vida dos professores, seja como um deles, seja como supervisora, convivendo com o cotidiano da vida da escola. 
Para isso, foi tomado, como referência, o calendário escolar considerado o elemento primeiro na ordenação do dia a dia de uma escola e as repercussões que trazem na organização do trabalho cotidiano e, sobretudo, no tempo vivido no recinto escolar.

A organização administrativa de cada atividade, com tempo definido, mostra-se necessária para gerir cada ação, que tem, porém, repercussão muito relevante na vida de cada um que vive um tempo duradouro no recinto escolar: constrói interações intensas, construtivas ou tensas, significativas ou frustrantes, na jornada diária, nas semanas e meses de trabalho.

A convivência duradoura na docência e na supervisão escolar, composta com o contato direto com uma escola do sistema de ensino, permitiu reunir observações atentas, diálogos francos, informações sensíveis sobre o modo como se vive o tempo na escola, a fim de levantar questões atinentes à qualidade desse tempo, despendido no espaço escolar, com consequências relevantes para a realização da vida pessoal e profissional dos que se dedicam ao ensino.

O tema do tempo escolar conheceu muitas iniciativas de mudanças e conta, ainda, com crescentes pesquisas desenvolvidas por pesquisadores interessados tanto em melhorar as condições de vida e de aprendizagem dos alunos quanto tornar os momentos de vida na escola um fator de bem-estar (TOUITOU; BEGUE, 2010).

Os projetos de melhoria desse tempo, as pesquisas e as conferências (CONFERÉNCE NATIONAL SUR LES RYTMMES SCOLARIES, 201 1), em geral, procuram analisar experiências em andamento e avaliar dispositivos para melhor distribuir, ampliar e qualificar o tempo consagrado à educação escolar, desejando superar uma concepção que se restrinja à duração cronometrada de atividades segmentadas e sucessivas, previstas pelos cânones administrativos do ano escolar. A finalidade das pesquisas e estudos é criar, nas atividades de ensino e de aprendizagem, uma oportunidade significativa de realização da vida como advogam alguns países (OCDE, 2011 ; EUROPEAN COMISSION, 2015/2016).

Se a duração dos tempos de ensino e a segmentação dos momentos de aprendizagem estiveram sempre presentes na organização da vida escolar, mais recentemente os sistemas de ensino têm tentado investir em experiências de recomposição do calendário e do horário diário, seja no alongamento da 
O tempo da escola: organização, ampliação e qualificação do tempo do ensino escolar

jornada escolar, seja na melhor adequação às necessidades dos alunos, ou, ainda, em formas alternativas e criadoras de distribuição de todos os momentos despendidos na educação escolar, assumindo diferentes pressupostos e objetivos.

Tempo escolar tratado, comumente, como a divisão mecânica da duração dos dias e das horas da vida escolar, é retomado com relevância para qualificar a experiência que acontece na escola: uma experiência de partilha comum de vida que compreende todos os tempos e todos os atores educacionais, comprometidos com o sucesso da educação: alunos, professores, pais e prestadores de serviços, além de gestores, políticos e profissionais de diferentes áreas. Ademais, Implica reavaliar os conteúdos de ensino e das práticas pedagógicas, e todos os âmbitos em que o tempo da vida se realiza: o trabalho, o lar, o transporte, a segurança e a saúde.

Mais que o mote pragmático de Benjamin Franklin - "tempo é dinheiro" - comenta Weber (2004, p. 42) é um conceito utilitarista. $\bigcirc$ tempo, porém, é sobretudo, a expressão da liberdade de poder ser o que cada um deseja ser e de se definir como pessoa autônoma na vida escolar e social.

Analisar a organização do tempo é, pois, dar atenção às possibilidades que cada um pode encontrar na realização pessoal em seu percurso de vida na escola e criar as melhores oportunidades de aprendizagem e bem-estar de todos os que estão comprometidos com a educação escolar.

Um retrospecto histórico do tempo escolar europeu, coordenado por Compère (1997), revela que a questão está no centro dos projetos de sociedade e é elemento central de todo o projeto de educação. Para outros, como Waaub (2006), o tempo escolar mantém-se herdeiro de uma organização taylorista do trabalho: um tempo mecânico e repetitivo, calcado na sucessão de tarefas simples consecutivas, fracionadas em aulas, exercícios, matérias e o tempo de trabalho, caracterizado pela presença física do aluno.

Identificar as críticas que são feitas ao tempo vivido na escola requer encontrar as indicações que visem à elevação da qualidade do tempo despendido no ensino escolar (LECONTE-LAMBERT, 2011 ) considerando que é próprio do ser humano estar imerso em uma temporalidade da qual deve ter consciência, para assumir, segundo Heidegger (2005), o próprio destino de forma autêntica. 


\section{Críticas e controvérsias}

A crítica ao tempo escolar ganhou maior relevância com o Relatório norte-americano da National Education Commision on time and learning (Necta), Prisioners of Time (NECTA, 2005). O relatório introduziu o debate crítico sobre o tempo de vida na escola ao mostrar que a organização desse tempo determina uma lógica de vida da escola: aprisiona todos os atores envolvidos - alunos, professores, gestores e famílias -, e, sobretudo, é determinante do ato pedagógico, do currículo e das condições de aprendizagem dos alunos.

O relatório contribuiu para difundir a ideia de que o aumento do tempo de ensino é a chave para elevar a qualidade da aprendizagem: aumentar o tempo escolar para todos contribui para a elevação do nível de competência dos alunos e de toda a sociedade. $O$ documento salienta, ainda, que, para maior equidade, é necessário destinar mais tempo para aqueles que, por desempenho insuficiente ou carências sociais, tenham maiores necessidades pedagógicas. O texto supõe que o tempo escolar mais extenso da jornada escolar ou "modulável" em função das diferentes necessidades pedagógicas dos alunos pode equalizar as diferenças de aprendizado com uma pedagogia diferenciada para alunos com maiores dificuldades e superar as desigualdades escolares.

relatório trouxe, também, de forma incisiva, a divisão, distribuição e fruição do tempo na escola para o centro dos sistemas de ensino: a organização do tempo não só como meio de sucesso escolar, mas também como elemento-chave de análise que compromete toda a vida da escola: abrange a organização de regimes de tempo integral, parcial, estendido; pressupõe a redivisão do ano, do mês, da semana, do dia, da hora, das férias e dos feriados; comporta o tempo dos conteúdos, das disciplinas, dos modos de ensinar; enfim, o tempo escolar está ligado a todas as transformações do tempo social, seja no trabalho, no lazer e no tempo livre, no transporte, nos espaços e nos lugares sociais.

Pensar o tempo na sua totalidade significa elevar a qualidade da vida escolar, sem guerra hostil entre atividades na escola e atividades extraescolares, isto é, fora da escola; ou atividades para-escolares, paralelas à escola; ou peri-escolares, logo, antes e depois da escola; ou, ainda, pós-escolares, que se seguem ao fim dos estudos. 
O tempo da escola: organização, ampliação e qualificação do tempo do ensino escolar

Muitas famílias esperam que todo o tempo de seus filhos na escola crie um processo mais aberto e original de aprender, que incorpore todas as oportunidades de aprendizagem, discrepante da segmentação constante do ensino disciplinar, a fim de promover a formação desejada pelas famílias, pela sociedade e pelas declarações oficiais dos sistemas de ensino.

tempo integral ou parcial tem uma atualidade inédita dado que alguns pesquisadores confrontam-se entre a necessidade de ampliação do tempo de vida escolar e outros que se opõem à progressiva invasão da escola na vida, na formação, no cotidiano e na vida familiar. É consenso, porém, que a simples ampliação do tempo não garante, necessariamente, mais sucesso na aprendizagem, tampouco é fator mais importante para a recuperação eficaz de aprendizagens não alcançadas, segundo Chopin (2011). Dados do Índice de Desenvolvimento da Educação Básica (ldeb) mostram que "[...] não há diferença de aproveitamento escolar entre alunos da rede normal e os que estudam nas 309 unidades com período estendido; no sistema, o aluno fica na escola da $7 \mathrm{~h}$ às $16 \mathrm{~h} 10 \mathrm{~m}$ e o currículo tem oito oficinas obrigatórias" (SALDAÑA, 2013 , p. 51.

Os investimentos na mudança das práticas pedagógicas e nas condi70 ções dadas ao trabalho docente podem ser positivos e alcançar mais êxito no ritmo da aprendizagem e no sucesso de alunos com maiores dificuldades. Por isso, em contraposição à extensão do tempo, há educadores que advogam, antes, dar maior qualidade ao tempo previsto, que, simplesmente, creditar mais tempo para obter melhor resultado de aprendizado. É preciso reconhecer que há tempos educativos intelectuais, culturais e estéticos, marginalizados pelo ensino escolar, que privilegiam uns conhecimentos em detrimento de outros. Há, também, tempos de vida e modos de transmissão e de avaliação do saber diferente do padrão convencional da escola, pouco valorizados na vida escolar (GAUSSEL, 2013).

No extremo dessas oposições à ampliação do tempo, há os que se opõem à invasão da escolaridade oficial, tida como indevida, na vida particular, supondo que atende melhor o tempo histórico da criança, e renegam a escola regular e sua pretensão monopolista da educação. Preferem retirar-se do processo totalizante do tempo escolar, rejeitando o que a escola oferece, para se aplicar a uma pluralidade de meios educativos e promover o ensino no recesso particular da família. 
Se, em outros sistemas de educação, é admissível a educação fora da escola regular, no Brasil, porém, o ensino fora da matrícula regular na escola só pode acontecer com autorização judicial, pois criança fora da escola enseja crime de abandono intelectual, previsto no Estatuto da Criança e do Adolescente, Lei n 8.069, de 13 de julho de 1990, que prevê, no art. 55: "Os pais ou o responsável têm a obrigação de matricular seus filhos ou pupilos na rede regular de ensino" (BRASIL, 1990, p. 13563); e, no art. 246 do Código Penal: "Deixar, sem justa causa, de prover à instrução primária de filho em idade escolar: Pena - detenção, de quinze dias a um mês ou multa" (BRASIL, 1940, p. 2391).

As mudanças sociais e as "mudanças da escola", quanto às finalidades sociais da escola, quanto ao público e ao currículo escolar e quanto a outras formas de ensino e de aprendizagem, convergem na urgência de reavaliar-se os limites e, sobretudo, as possibilidades do tempo de formação escolar. Se esse tempo tem sido definido por um conceito administrativo de gestão de pessoas, e determinado, em conformidade, como tempo contratual de hora-aula, hora-disciplina ou hora de gestão dos serviços escolares, ele cria, em última análise, um estilo que Maulini e Perrenoud (2005) descrevem como a "forma escolar" da organização pedagógica do tempo.

$\bigcirc$ relatório Necta mostra que a vida da escola está definida a partir do contrato dos professores e, em muitos aspectos, distante dos interesses e das necessidades dos alunos, e motivo de muitas críticas à desatualização do ensino em face da diversidade de tempos educativos e da inércia dos sistemas de ensino diante das novas formas de se dispor do tempo de aprendizagem escolar (CAVET, 2011 ).

Análises comparativas internacionais produzidas pela Organização para a Cooperação e Desenvolvimento Econômico (OCDE) (20 1 2-20 13 ) revelam que a distribuição do tempo nos calendários dos sistemas de ensino é, comparativamente, muito diferente nos diversos sistemas nacionais de ensino, dadas suas especificidades históricas, culturais, políticas, ambientais e socioprodutivas. A rede de informações Eurydice (201 2-2013) mostra as diferenças nas escolas europeias no que se refere à totalidade do tempo escolar e à extensão desse tempo no calendário anual, seja quanto ao número de semanas e dias por ano, incluindo férias e feriados, seja quanto à duração semanal e diária do tempo escolar (EUROPEAN COMISSION, 2013). 
O tempo da escola: organização, ampliação e qualificação do tempo do ensino escolar

A organização adequada do tempo anual escolar de duzentos dias letivos está na agenda da política educacional brasileira, consideradas as especificidades regionais e locais de um território extenso, geograficamente complexo, ambientalmente diverso. Além dessas condições, o tempo escolar está atravessado tanto por confrontações entre diferentes agentes sociais, econômicos, comerciais, turísticos, como ocorreu com a Copa Mundial de Futebol em 2014, quanto por interesses conflitantes entre aspirações familiares e o desempenho de seus filhos, ou entre as possibilidades reais dos docentes e as necessidades objetivas dos alunos.

Mais recentemente, a ampliação do tempo escolar, no Brasil, tem sido proposta por diferentes instâncias estaduais ou municipais para elevar a duração e a qualidade, com diferentes pressupostos e objetivos, gerando variações nominais e conceituais - educação de tempo integral ou de ensino integral, de tempo estendido, de atividades no contraturno escolar, e outras com a finalidade de atender a uma das metas do Plano Nacional de Educação e, desse modo, equipar-se a outros sistemas internacionais de educação.

\section{O tempo escolar: calendário e matriz curricular}

Calendário Escolar e a Matriz Curricular regulamentam e gerenciam o tempo escolar. Por isso, a análise do ritmo do tempo em uma escola tomou, primeiramente, o calendário como referência jurídico-administrativa da regulação administrativa dos dias letivos e horas das atividades dos atores educacionais e, ao mesmo tempo, as incidências cotidianas que afetam os momentos de uma escola.

Elegeu uma escola metropolitana do sistema estadual de ensino médio, situada na região metropolitana do Estado de São Paulo, para levantar as questões sobre a divisão e distribuição do tempo que envolvem o regime diário do ensino dessa escola, tendo, como premissa, a analogia possível com o regime do tempo de muitas outras escolas. Está focado, sobretudo, no Ensino Médio. Ainda que as questões sejam semelhantes, o Ensino Fundamental e a Educação Infantil têm muitas particularidades.

acompanhamento da vida de uma escola singular considera que ela condensa, apesar de muitas diferenças, os principais problemas que ocorrem em outras unidades de ensino em relação à distribuição e vida escolar. 
Essa distribuição é dada, sobretudo, por documentos legais que definem cada momento da escola: Calendário Escolar e Matriz Curricular. A leitura desses textos pode, à primeira vista, parecer óbvia para quem está no ambiente escolar, mas uma leitura atenta revela que todo significado do tempo tende a esgotar-se no cumprimento burocrático das prescrições legais desses documentos, sem consideração pela virtude dos momentos de vida de cada serviço.

Não foi pretensão propor as "melhores práticas" de solução às questões relativas à distribuição do tempo de docência e aprendizagem, mas situar a relevância de se dar uma atenção especial ao ritmo do tempo na escola, sem confiná-lo, quase exclusivamente, às exigências burocráticas.

$\bigcirc$ instrumento oficial de regulação do tempo escolar é definido, anualmente, por meio do calendário escolar. $\bigcirc$ ano escolar é determinado, institucionalmente, por uma série de legislações específicas que guiam os dias, as horas e os minutos, tendo como matriz regulatória a Lei de Diretrizes e Bases da Educação Nacional - LDB 9.394, de 20 de dezembro de 1996, que determina, em seu Artigo 8, que: "A União, os Estados, o Distrito Federal e os Municípios organizarão, em regime de colaboração, os respectivos sistemas de ensino" (BRASIL, 1996, p. 27834), e, em seu artigo 24, item I, a Lei estabelece para todo o território nacional "[...] a carga horária mínima anual de oitocentas horas, distribuídas por um mínimo de duzentos dias de efetivo trabalho escolar, excluído o tempo reservado aos exames finais, quando houver" (BRASIL, 1996, p. 27836). Pode-se inferir do artigo a fixação de turno diário de quatro horas.

A carga horária mínima pode ser ampliada, estendendo o tempo diário; os dias não podem ser diminuídos. Outros sistemas internacionais dividem o ano por semanas, situando-se, na média, entre 38 a 40 semanas (OCDE, 2011 1; no caso brasileiro, 40 semanas.

A partir dessa prescrição legal e respeitando o regime de colaboração entre as unidades federadas, cada Estado, o Distrito Federal e os Municípios, organizam-se, legalmente, estabelecendo o tempo físico escolar para os respectivos sistemas de ensino.

$\bigcirc$ Brasil segue, de modo geral, um padrão internacional típico de ano escolar, não menor que nove meses, organizado por semestres, bimestres, meses, semanas e dias, variando conforme o nível, ou tipo de instituição de 
O tempo da escola: organização, ampliação e qualificação do tempo do ensino escolar

ano escolar e intercalado com dois períodos de férias. A média entre os países da OCDE é de 187 dias letivos, em geral, de oito horas diárias (OCDE, 20111 .

Os duzentos dias letivos, no Brasil, são intercalados, em geral, de trinta dias em julho e as férias de verão (final-início de ano) - trinta dias em dezembro e em janeiro. Às férias somam-se os nove feriados nacionais e os pontos facultativos nacionais, fixados em número de sete, os feriados estaduais, até oito, e municipais até quatro feriados, incluídos o dia do município e a Sexta-feira Santa. No caso brasileiro, a LDB, no artigo 23, prevê que a organização pode ser

[...] em séries anuais, períodos semestrais, alternância regular de períodos de estudos, grupos não seriados com base na idade ou em outros critérios, ou por forma diversa de organização, sempre que o interesse do processo de aprendizagem assim o recomendar (BRASIL, 1996, p. 27836).

As peculiaridades regionais são muito diversas e mereceriam estudos específicos sobre o calendário de cada região ou estado, que este texto não comporta. Por isso, esta análise do tempo escolar toma, como referência, o 74 calendário escolar das escolas de Educação Básica estaduais do Estado de São Paulo.

O sistema de educação do Estado de São Paulo, no ano de 2014, segundo dados do Instituto Brasileiro de Geografia e Estatística (IBGE), compreendia 645 municípios e uma população de 44.035.304. A dimensão do sistema e a complexidade das demandas abarcam, mutatis mutandis, os problemas mais significativos da gestão do ano escolar da Educação Básica no Brasil.

○ calendário escolar é seguido com algumas adaptações pelas escolas particulares e pelos sistemas municipais de ensino e, de modo geral, não difere muito do calendário de outros estados da federação.

$\bigcirc$ ano letivo no Estado é de dez meses, organizado em dois semestres e estes, em dois bimestres, ao fim dos quais há um período de avaliação e de atribuição de notas aos alunos. Ao final do ano letivo, a partir da somatória geral da pontuação alcançada pelo aluno no término desses períodos, juntamente a sua assiduidade, é calculada sua média final para efeito de promoção ou retenção escolar. 
mês escolar é formado em média por quatro semanas. A cada final de mês, a frequência dos professores é lançada em sistema próprio de controle e é gerado o pagamento mensal desse profissional. A semana é formada por cinco dias, de segunda a sexta, acrescido, em algumas escolas, de mais um período aos sábados.

$\bigcirc$ dia escolar é dividido em três períodos, tendo os diurnos uma duração, em média, de cinco horas e o noturno, de quatro horas. Ao aluno é permitida a permanência em dois períodos diurnos no caso de sistemas de ensino integrais ou em um período, no caso de sistemas não integrais. Há escolas que mantêm o período noturno; outras não, dependendo da demanda escolar da região.

A organização temporal do ano é registrada em dois documentos próprios da gestão escolar: Calendário Escolar e Matriz Curricular. $\bigcirc$ calendário escolar é seguido por todo o sistema de ensino estadual, respeitadas as particularidades locais, regionais, festivas e turísticas de cada município, garantidos os duzentos dias letivos. Toda alteração que vier a ser feita no calendário deve prever o ajuste nas atividades complementares, conexas com o calendário, tais como as diárias dos serviços de alimentação e de transporte, que dependem de outras instâncias administrativas ou de serviços contratados, pois essas alterações pressupõem, também, a previsão da interrupção desses outros serviços, sem os quais pode haver custos adicionais. A incursão das disposições do calendário indica a soberania do diploma legal na regência de todos os momentos da escola, adotado como o meio regulamentar de viver a realização da vida no trabalho escolar.

\section{O tempo escolar nas escolas estaduais de Ensino Médio}

A delimitação do tempo escolar nas escolas estaduais de Ensino Médio do Estado de São Paulo começa, quando, no início da cada ano letivo, uma legislação intitulada de Resolução, publicada pela Secretaria Estadual de Educação do Estado é divulgada, estabelecendo as diretrizes para a organização curricular da Educação Básica nas escolas estaduais, juntamente às orientações para a elaboração do Calendário Escolar e da Matriz Curricular.

A cada ano, uma nova Resolução é publicada, considerando as particularidades temporais do ano base. 
O tempo da escola: organização, ampliação e qualificação do tempo do ensino escolar

A referência básica para a elaboração dessa Resolução é o número de matrículas oficiais do Censo Escolar do ano anterior. Em 20131, a Rede estadual paulista de escolas contava com mais de quatro milhões de alunos, distribuídos em mais de cinco mil e quinhentas escolas estaduais, jurisdicionadas a noventa e uma Diretorias de Ensino. Acresce-se a isso, a necessidade de organizar a carga horária prevista para mais de duzentos mil professores e o horário de trabalho dos mais de sessenta mil servidores da "rede escolar", designação usual para se referir ao sistema de educação estadual.

Cada escola organiza, com base na Resolução, seu Calendário Escolar, considerando todas as questões atinentes ao horário do transporte de alunos, horário de professores, entre outros, mediante um esquema matemático, sendo especificado, por código, todos os dias letivos, férias, feriados, recesso escolar e demais atividades anuais previstas na escola.

Para facilitar a elaboração do calendário, as Diretorias de Ensino sugerem um modelo a ser seguido, que resulta no Quadro 1 esquematicamente desenhado, com um espaço quadriculado para cada dia do ano tendo, obrigatoriamente, que somar, ao final, no mínimo, duzentos dias letivos².

\section{Quadro 1}

\section{Modelo de Calendário Escolar oficial - ano 2012}

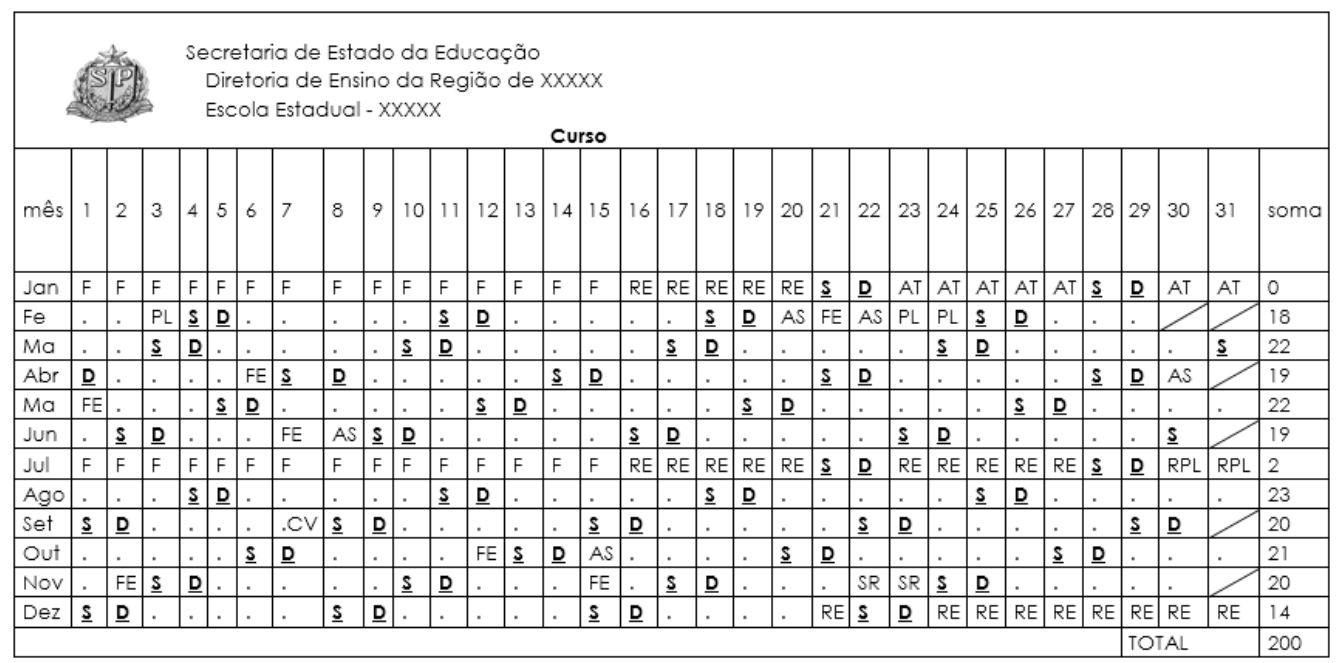

Fonte | Portal da Secretaria Digital Escolar do Estado de São Paulo ${ }^{3}$ 
Dia letivo é dia de presença física de professores e alunos na escola, envolvidos em atividades de aprendizagem, caracterizando dia efetivo de trabalho escolar. Constam como dias letivos as atividades programadas, realizadas fora do recinto da sala de aula ou da escola, desde que comprovadas as presenças físicas de professores e de alunos envolvidos em atividade de aprendizagem. Dias letivos como as atividades programadas são discriminados com códigos específicos.

O Quadro 1 apresenta alguns códigos próprios: recesso (RE), o afastamento legal do professor da escola por período fixo, férias (F), período de afastamento da escola com remuneração financeira própria ao período. As férias e o recesso tornam os meses de janeiro, julho e dezembro períodos quando as aulas permanecem suspensas.

Os outros códigos referem-se aos sábados (S) e domingos (D), período reservado para atribuição de aula (AT), atividades suspensas (AS), dia de planejamento (PL), replanejamento (RPL), comemoração cívica (CV) e dia da avaliação externa oficial intitulada Saresp ${ }^{4}$ (SR). Os quadrículos pontuados indicam dias letivos.

Tomando como base o Quadro 1, os dias assinalados e os códigos lançados, na realidade, contabilizam-se cento e noventa e dois dias letivos. No entanto, é preciso ainda deduzir desse número as ocorrências pontuais de ausências de professores, feriados municipais, festas ou eventos de cada região ou escola. Eventuais modificações no calendário, no decorrer do ano, deverão ser solicitadas, oficialmente, via Diretoria de Ensino.

Um segundo documento que rege o tempo é a Matriz Curricular preparada pela escola no início de cada ano e enviada para homologação superior, junto ao Calendário. Esse documento especifica a duração das aulas em minutos, o número de aulas por dia, por semana e por ano letivo. Há um modelo para cada modalidade de ensino. $\bigcirc$ Quadro 2 apresenta a Matriz Curricular para o Ensino Médio: 
O tempo da escola: organização, ampliação e qualificação do tempo do ensino escolar

Quadro 2

Matriz Curricular do Ensino Médio

\begin{tabular}{|c|c|c|c|c|c|}
\hline \multicolumn{6}{|c|}{ Matriz Curricular - Ensino Médio - Diurno } \\
\hline \multicolumn{6}{|c|}{$N^{\circ}$ de aulas semanais de acordo com o ano cursado } \\
\hline \multirow{12}{*}{ 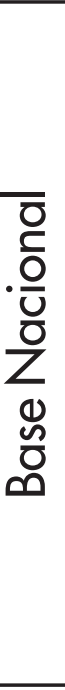 } & Área & Disciplina & $1^{\circ}$ & $2^{\circ}$ & $3^{\circ}$ \\
\hline & \multirow{3}{*}{$\begin{array}{l}\text { Linguagens e Códigos } \\
\text { e suas Tecnologias }\end{array}$} & Língua Portuguesa & 5 & 5 & 5 \\
\hline & & Arte & 2 & 2 & 2 \\
\hline & & Educação Física & 2 & 2 & 2 \\
\hline & \multirow{4}{*}{$\begin{array}{l}\text { Ciências da Natureza } \\
\text { Matemática e suas } \\
\text { Tecnologias }\end{array}$} & Matemática & 5 & 5 & 5 \\
\hline & & Biologia & 2 & 2 & 2 \\
\hline & & Física & 2 & 2 & 2 \\
\hline & & Química & 2 & 2 & 2 \\
\hline & \multirow{4}{*}{$\begin{array}{l}\text { Ciências Humanas } \\
\text { e suas Tecnologias }\end{array}$} & História & 2 & 2 & 2 \\
\hline & & Geografia & 2 & 2 & 2 \\
\hline & & Filosofia & 2 & 2 & 2 \\
\hline & & Sociologia & 2 & 2 & 2 \\
\hline \multirow{2}{*}{\multicolumn{2}{|c|}{ Parte diversificada }} & Língua est Moderna - Inglês & 2 & 2 & 2 \\
\hline & & Total geral & 30 & 30 & 30 \\
\hline
\end{tabular}

Fonte | São Paulo (201 1)

Essa mesma Matriz Curricular, para o período noturno do Ensino Médio, contabiliza vinte e cinco aulas semanais, sendo cinco aulas diárias, com duração de 45 quarenta e cinco minutos cada uma, totalizando mil e oitenta aulas anuais.

A Matriz Curricular, no Ensino Médio, apresenta uma lógica centrada estritamente em disciplinas, cada uma autônoma, com horário definido, docente específico, conteúdo e avaliações próprias, hierarquicamente distribuídas por áreas, cabendo a cada disciplina impregnar o conteúdo científico com as questões "vivas" que os alunos vivenciam. As fronteiras autônomas de cada disciplina delimitam os próprios objetivos, estratégias e avaliações e tendem a confinar-se à informação dos conteúdos específicos, apoiando-se na 
expectativa de que as disciplinas, por si, ou por iniciativa original de um ou outro professor, transcenderão os limites das informações dadas e possibilitarão ao aluno a compreensão da vida social, ética e política, e, no extremo do otimismo, formarão cidadãos ativos e participantes.

A hora aula, quanto aos minutos que a compõem, torna-se a unidade de medida e instrumento de divisão do tempo da disciplina e do trabalho do professor. Uma hora aula, uma disciplina, um professor, tudo isso constitui o princípio único que organiza o ensino, a gestão escolar e todas as atividades pedagógicas. Essa disposição rígida do tempo, calcada, quase exclusivamente, na hora-aula do professor e na sua respectiva disciplina, pouca atenção dá ao aluno, obrigando-o a recomeçar, sucessivamente, um novo conteúdo, com outro docente, com outras estratégias e exigências pedagógicas, em cada etapa do horário, sem tempo suficiente para a assimilação, a reflexão e o amadurecimento criativo. No decorrer de cada período letivo diário, dividido entre várias horas-aula, com um corte radical de cada conteúdo disciplinar, com exato início e fim de cada aula, sucessivamente substituídas por novos conteúdos de aprendizagem, esgotam a atenção do aluno e arrefece sua motivação. Cabe ao aluno moldar-se a essa disposição do tempo escolar, sem outros apoios para situar-se nessa abrupta mudança de docentes, de regime de aulas e de organização partilhada de suas atividades.

Uma vez homologados, cabe à equipe gestora da escola encaixar as aulas dos professores dentro de determinado período, geralmente, composto de três turnos diários, com seis aulas de cinquenta minutos no período diurno, e, no período noturno, com cinco aulas de quarenta e cinco minutos.

Os períodos escolares, independentemente das particularidades zonais ou regionais, devem ter seu início e término sempre nos mesmos horários para todas as escolas públicas estaduais da região, visto que essas estão vinculadas à organização e à contratação, por órgão superior, do transporte escolar, com a garantia de locomoção que atenda aos horários dos três períodos diários de aula.

\section{Um exemplo típico da disposição do tempo escolar}

Visando à compreensão dessa logística do tempo, a investigação tomou como base de observação, uma escola que, pelo número de alunos e 
O tempo da escola: organização, ampliação e qualificação do tempo do ensino escolar

de professores, é considerada pela SEE uma escola de proporção média, com três turnos diários de aula, comportando sessenta professores, trinta salas de aula com uma média de quarenta alunos por sala, vinte funcionários, computando-se agentes do Estado e contratados, e uma equipe gestora composta de cinco pessoas, com horário fechado, idêntico ao de outras escolas públicas da região. $\bigcirc$ registro semanal do tempo escolar dessa escola está configurado no Quadro 3 a seguir

\section{Quadro 3}

Horário semanal de aula de uma escola da Rede pública estadual do Estado de São Paulo - Educação Básica

$\begin{array}{cccc}\text { Aulas } & \text { Período } & \text { Período } & \text { Período } \\ & \text { Manhã } & \text { Tarde } & \text { Noite } \\ 1^{\text {a }} \text { aula } & 7: 20-8: 10 & 13: 00-13: 50 & 19: 00-19: 45 \\ 2^{\text {a }} \text { aula } & 8: 10-9: 00 & 13: 50-14: 40 & 19: 45-20: 30 \\ 3^{\text {a }} \text { aula } & 9: 00-9: 50 & 14: 40-15: 30 & 20: 30-21: 15 \\ \text { Intervalo } & 20 \text { minutos } & 20 \text { minutos } & 20 \text { minutos } \\ 4^{\text {a }} \text { aula } & 10: 10-11: 00 & 15: 50-16: 40 & 21: 35-22: 20 \\ 5^{\text {a }} \text { aula } & 11: 00-11: 50 & 16: 40-17: 30 & 22: 20-23: 00 \\ 6^{\text {a }} \text { aula } & 11: 50-12: 40 & 17: 30-18: 20 & \end{array}$

Fonte | Documento interno de uma escola pública estadual de Educação Básica

A jornada diária é fragmentada em seis espaços, no caso do período diurno; e cinco espaços no noturno, intercalados por um intervalo de vinte minutos, após a terceira aula. Em cada aula de cinquenta minutos, o professor dispõe de um tempo fixo para sua disciplina: inicia sempre com a chamada dos alunos para registrar possíveis ausências. Nessa etapa da aula, cinco a dez minutos são gastos, restando, apenas, mais quarenta minutos, ou trinta no caso do período noturno -, para organizar e expor o conteúdo planejado e finalizá-lo, se possível, na mesma aula. Consumidos os dez minutos iniciais em cada aula para constatar presenças, é possível verificar que, diariamente, em um período de seis aulas diárias, sessenta minutos são dedicados à chamada dos alunos presentes, restando, portanto, quatro horas diárias de aula, que, 
computando-se o período do intervalo, transforma-se em três horas e quarenta minutos.

É preciso subtrair, ainda, dessas três horas e quarenta minutos, os períodos de trocas de professores pelas diversas salas de aula. Os professores levam, em média, cinco minutos para essa movimentação, com mais algum tempo para organizar os alunos, em geral, dispersos, durante esses momentos de troca de professores. Ao final, somam-se, aproximadamente, três horas de aulas diárias.

O intervalo entre as aulas e o intervalo formal de vinte minutos, após a terceira aula, representam, para os alunos, momentos agradáveis de descanso e socialização entre amigos, com conversas animadas e diversas brincadeiras, espaço e tempo de comunicação e vida livre, no turbilhão de informações fragmentadas em cada momento. $\bigcirc$ fracionamento constante não proporciona uma comunicação amistosa que poderia tornar esses intervalos em momentos educativos especiais.

Ao início e ao final de cada aula, um som estridente da campainha ecoa por todo o ambiente escolar, assinalando, de modo incessante, sete ou oito vezes, o princípio e o fim de cada nova atividade; o recomeço de outro conteúdo disciplinar; a presença de novo professor.

A pulverização constante do tempo dilui a concentração e dispersa a atenção. A hora-aula minutada, definida em função do horário de trabalho do professor, atende pouco o interesse efetivo do aluno. Essa rigidez da divisão do tempo em hora-aula-professor, única medida de disposição da jornada escolar, tem sido objeto de estudos, para alcançar melhor adequação do ritmo da vida escolar em benefício do ensino e da aprendizagem, como alguns sistemas preconizam (FRANCE, 2011 ).

Um episódio constante, observado durante um ano escolar, é a composição do tempo de trabalho de todos os seus professores; assim, a escola, aqui exemplificada, deve compor o horário para que os seus sessenta professores possam iniciar as suas aulas. Para isso, deve considerar o número de aulas de cada professor, sua disponibilidade pessoal, a carga horária legal permitida por dia, observando o limite de aulas de cada disciplina por sala.

Nessa fase, tem início uma luta de cada professor para que a escola crie "seu" horário pessoal, de forma que possa conciliar seu tempo particular com o tempo escolar. Todo início de ano letivo, nessa fase, ocorrem frequentes 
O tempo da escola: organização, ampliação e qualificação do tempo do ensino escolar

conflitos entre os professores e a equipe gestora por conta dessa difícil adequação do tempo de cada professor, resultando, às vezes, em representações legais contra o Diretor da escola por parte do professor, porque o professor sentiu-se prejudicado na pretensão de dispor do seu tempo pessoal, compatível com suas outras atividades.

Um conjunto de conflitos resulta de muitas situações particulares: como suas aulas ocorrem, também, em outras escolas, distantes ou distanciadas, a compatibilidade de horário pode ficar problemática para completar a carga horária de trabalho. Um tempo precioso de vida é dispendida nos ajustes convenientes a cada pretensão dos docentes. Outras questões surgem: o limite dado pela lei trabalhista quanto ao número de aulas diárias a serem ministradas pelo professor; o cumprimento integral da Matriz Curricular; os impedimentos pessoais, em determinados dias e horários, relativos à sua vida privada, entre outros, tornam a formatação do horário diário escolar um grande e, às vezes, conflituoso quebra cabeça para compor o tempo da educação escolar. Entre esses conflitos, um dos mais problemáticos é quando o professor ministra aulas em mais de um estabelecimento, pois seu horário deve contemplar, além das aulas, o tempo de trânsito entre as escolas. Os conflitos são reveladores da

82 precariedade do trabalho docente e indicam que, sem o tempo integral dos professores na escola, pouco adiantará alongar a duração da jornada escolar.

Estabelecido o horário da escola, qualquer modificação durante o ano, pode acarretar ajustes complexos seja de outros professores, seja de outras escolas, em razão da sua carga horária já definida. Além do cuidado com o horário dos professores, é preciso, ainda, ajustar o horário de seus vinte funcionários, de acordo com o período de aula, garantindo: condições para que os alunos tenham merenda no horário do intervalo; limpeza do ambiente durante todo o dia; acompanhamento por funcionários durante o intervalo; atendimento adequado da secretaria da escola e de outros setores, que, por sua vez, devem atender a toda a comunidade, quando a escola estiver em funcionamento. O tempo de vida na escola é avassalado por ajustes na composição de cada demanda dos professores e funcionários; cabendo aos alunos proceder aos ajustes dos acordos burocráticos em torno dos horários estabelecidos para o funcionamento da escola.

Passada a complexa fase da montagem do horário das aulas diárias da escola e dos funcionários, tem início a gestão anual do Calendário e da Matriz Curricular, para atender aos seus, em média, mil e duzentos alunos. 
Embora a escola lute por autonomia de sua gestão, essa autonomia passa a ser algo distante da realidade diária escolar, devido a dias, tais como: reuniões para discussão de temas sugeridos pela Secretaria Estadual de Educação, planejamento, avaliações institucionais, recesso/férias dos professores, suspensão de atividades e aplicação de avaliações externas, os quais estão determinados no Calendário.

Essas determinações são necessárias para garantir e organizar, também financeiramente, alguns itens que envolvem atenção e tempo, como o transporte de alunos, que deve ser contabilizado em sistema próprio de controle financeiro do Estado, quando não houver aula nas escolas, o passe escolar não seja contabilizado e o transporte fretado seja suspenso, pois as quantias financeiras envolvidas, nessa ação, movimentam recursos significativos ${ }^{5}$.

Outro item que também envolve tempo e cuidados especiais diz respeito à merenda servida, diariamente, nas escolas públicas. Nos dias em que não há a presença de alunos ou eles estão em número reduzido, a escola não deve fazer a merenda ou deve fazê-la em menor quantidade, para garantir o controle dos altos gastos envolvidos ${ }^{6}$.

\section{Considerações à guisa de conclusão}

O acompanhamento do tempo vivido na escola é revelador tanto da necessidade quanto das possibilidades de se criar dimensões de vida, e mostra como as oportunidades de criar um tempo de trabalho virtuoso esgotam-se no exercício de ajustamentos formais, comprometendo, assim, o significado existencial de cada momento de vida dos atores educacionais.

Expostos às exigências parcelares de cada momento, cada instante dos docentes tende a se esgotar no cumprimento obrigatório das prescrições legais. Momentos de convívio e de comunicações interpessoais são muito limitados, trocas de reflexões profissionais ou manifestação de dúvidas cotidianas são quase impossíveis. Elas vão se avolumando a cada dia e, sem meios de se exprimirem, provocam sentimento agudo de isolamento solitário. A lógica que rege a temporalidade cotidiana, como se pode extrair tanto da literatura internacional quanto de observações conviviais sobre o ritmo do tempo de uma escola, é a hora-aula do docente, constrangido a cumprita nos horários 
O tempo da escola: organização, ampliação e qualificação do tempo do ensino escolar

prescritos e confinada em uma sala da aula, fora da qual não há outros elos de convivência, diálogo e escuta sensível.

A vida das famílias é, também, muito afetada pelo ritmo do tempo da escola. Para muitos pais, a escola, entre outros benefícios, é um local seguro onde eles podem deixar seus filhos durante seu horário de trabalho. Qualquer alteração na duração do ritmo do tempo escolar afeta muito a rotina familiar e gera atritos e constantes reclamações contra as interrupções na duração da vida escolar, pois muitos pais não têm estrutura familiar para manter, no lar, com segurança, seus filhos em idade escolar.

A otimização do tempo escolar está, na verdade, na confluência de afrontamentos entre interesses sociais divergentes, que envolvem as demandas dos professores, as necessidades dos alunos, a realidade social e as aspirações das famílias; além de atores econômicos, empresariais, comerciais e turísticos, em muitas ocasiões, conflitantes com o ritmo da vida escolar.

Por todas essas reflexões a análise crítica e a alocação do tempo escolar estão no centro das reformas dos sistemas de educação em todo o mundo, como atesta a literatura sobre a questão, e revelam-se necessárias para quem, deliberadamente, ingressa em uma escola, para observar com atenção e partilhar, criticamente e com emoção, do ritmo do tempo e da vida de uma escola. Quem envereda pelo tema, seja por uma pesquisa bibliográfica, seja por investigação aderente ao que acontece no dia a dia de uma escola, tem a necessidade de encontrar uma nova dinâmica no ritmo do tempo escolar, atestada pelas avaliações dos sistemas de ensino e, silenciosamente, desejada pelos que estão, duradouramente, no ambiente escolar.

A distribuição do tempo não pode se limitar à mera divisão de horas, dias e semanas, pois o ritmo do tempo afeta a vida pessoal de cada um. Ademais, atinge o modo de ensinar, o conteúdo do ensino e envolve todos os atores da educação: professores, pais, gestores e a sociedade, em geral.

No Brasil, a ampliação e a qualificação do tempo escolar são, também, objetivos das políticas públicas de educação nacional, estaduais e municipais. Muitas iniciativas têm sido introduzidas pelos estados e por muitos municípios na Educação Básica para ampliar o tempo e sua qualidade, tais como a escola de tempo integral, de ensino integral, de tempo estendido, atividades no contraturno escolar, além de projetos para permitir o livre trânsito de alunos durante todo o tempo em que a escola estiver aberta, para uso de 
equipamentos esportivos, recreativos, artísticos, de informática, entre outros. Essas iniciativas visam atingir um padrão condizente com novas exigências dos sistemas de ensino da educação, já alcançadas por muitos sistemas de ensino internacionais. Essas iniciativas brasileiras são algumas bem-sucedidas; outras, incipientes e precárias; todas, porém, desejando elevar a qualidade da educação e do tempo de aprendizagem na escola, tal como prevê a estratégia 6.1 do PNE (Plano Nacional de Educação).

Questão relevante é o tempo da vida do professor. Ele não pode ser mero usuário do tempo, mas autor da mudança significativa no tempo de vida do aluno. A passagem do aprendizado espontâneo do aluno ao conhecimento sistematizado, a transição de um convívio familiar ao convívio social, o despertar da curiosidade do aluno para compreender a si mesmo, a natureza circunstante, a realidade ambiental e social em que vive, são oportunidades que a escola deve oferecer para mudar, significativamente, o tempo da vida dos estudantes. Isso demanda espaço para convívio prazeroso, tempo de diálogos interpessoais para que o professor seja o artífice de um processo criador de tempos significativos de vida, que se torna impossível, quando há, somente, momentos ocasionais de contatos humanos, frequentemente tumultuados pelas exigências formais dos contratos hora-aula.

É, pois, precondição para transformar o ritmo de vida escolar o professor de tempo integral em uma única escola, para garantir a dedicação e um planejamento integrado e participativo de todas as atividades educacionais. Sem a formação de uma equipe, coesa e permanente, não há ensino que vingue. A divisão das horas de docência em vários estabelecimentos obriga o professor a ir de uma escola para outra, durante o dia, fracionando, totalmente, o tempo diário com o transporte, com espaços físicos diversos e readaptações constantes, cansativas, com prejuízo pessoal e, sobretudo, com o comprometimento do ritmo de vida da escola.

Os estudos cronobiológicos e as pesquisas cronopsicológicas de Touitu e Begue (2010) mostram que o ritmo biopsicológico dos alunos, em idades e horários diferentes, não têm um ritmo igual, tampouco é linear. Pelo contrário, é muito diverso, com momentos diários de concentração ótima e menor vigilância. Estudos preconizam que a excelente organização da jornada escolar e a sequência das aprendizagens mais exigentes de reflexão atentam para os tempos de maior ou menor disposição e atenção do aluno para o sucesso do ensino. 
O tempo da escola: organização, ampliação e qualificação do tempo do ensino escolar

Questão não menos importante é a arquitetura das escolas, em geral, divididas em salas seriadas e administrativas. $\bigcirc$ lugar onde se vive o tempo da vida, como os tempos do ensino, depende, também, da estrutura física da escola para prever a possibilidade de outras atividades interdisciplinares, que não se limitem à hora-aula na sala de aula, mas sejam convidativos à permanência mais efetiva dos alunos na escola, tal como preconiza a estratégia 6.2 do PNE:

As transformações da vida social, a vida das famílias, o trabalho dos pais, a atração dos meios de comunicação, o transporte, as festas e os eventos locais têm transformado, substantivamente, o ritmo do tempo e da vida tanto da sociedade quanto dos indivíduos. São dados que não podem ser ignorados, pois têm grande influência na equalização dos tempos escolares com o conjunto da vida social e redundam no encanto ou na frustração dos tempos de quem aprende e ensina. $O$ reconhecimento dessas mudanças e temporalidades dos alunos pode ensejar a necessidade de uma pluralidade de momentos de aprendizagem.

No Brasil, como em muitos outros países, há um grande esforço a ser realizado para melhorar a duração e a qualidade do tempo da educação 86 escolar, em razão das demandas sociais e dos avanços trazidos pela reflexão, pelas experiências inovadoras e pelas pesquisas. Analisar as possibilidades de qualificar o tempo vivido no ambiente escolar seja dos alunos, seja dos professores e gestores é uma urgência indeclinável, seja da pesquisa ou da reforma da educação, sob pena de agravar frustrações de muitas vidas dedicadas à educação escolar.

\section{Notas}

1 Disponível em: http://www.educacao.sp.gov.br/a2sitebox/arquivos/documentos/670.pdf. Acesso em: 26 mar. 2015.

2 Artigo 24 da LDB 9394/96: "A educação básica, nos níveis fundamental e médio, será organizada de acordo com as seguintes regras comuns: I - a carga horária mínima anual será de oitocentas horas, distribuídas por um mínimo de duzentos dias de efetivo trabalho escolar, excluído o tempo reservado aos exames finais, quando houver". (BRASIL, 1996, p. 27836). 1

Disponível em: http://www.educacao.sp.gov.br/a2sitebox/arquivos/documentos/670.pdf. Acesso em: 26 mar. 2015.

3 Disponível em: sed.educacao.sp.gov.br. Acesso em: 12 set. 2015.

4 Sistema de Avaliação de Rendimento Escolar do Estado de São Paulo. 
5 Só no período de 2008 a 2012, segundo a Lei Orçamentária Anual (LOA) e Balanço Financeiro do período, foram previstos e gastos mais de seiscentos milhões de reais.

6 Esse controle é indispensável não só pela qualidade da merenda servida, mas também pelos altos gastos públicos envolvidos. Entre o repasse da União ao Estado e os fundos do próprio Estado, no caso do Estado de São Paulo, tomando novamente como base o período de 2008 a 2012 , os gastos contabilizados ficaram na casa dos cento e oitenta milhões de reais.

\section{Referências}

BRASIL. Decreto-Lei no 2.848, de 7 de dezembro de 1940. Diário Oficial [da] República Federativa do Brasil, Poder Legislativo, Brasília, 31. dez. 1940, p. 2391.

Lei n 8.069, de 13 de julho de 1990. Dispõe sobre o Estatuto da Criança e do Adolescente e dá outras providências. Diário Oficial [da] República Federativa do Brasil, Poder Legislativo, Brasília, 16 jul. 1990. Seção 1, p. 13563.

Lei $n^{\circ}$ 9.394, de 20 de dezembro de 1996. Estabelece as diretrizes e bases da educação nacional (LDB). Diário Oficial [da] República Federativa do Brasil, Poder Legislativo, Brasília, 23 dez. 1996. Seção 1, p. 27833-27841.

CAVET, Agnès. Rytmes scolaries: pour une dynamique nouvelle des temps éducatifs. Dossier d'actualité de la VST, n. 60, fev. 2011 . Disponível em: http://www.inrp.fr/vst/ LettreVST/60-fev-2011. php. Acesso em: 2 maio 2015.

CHOPIN, Marie-Pierre. Le temps de l'enseignement: I'avancée du savoir et la gestion des héterogénités dans la classe. Rennes: Presses Universitaires de Rennes, 2011.

COMPÈRE, Marie-Madeleine. Du collège au lycée (1500-1850). Généalogie de I'enseignement secondaire français. Paris: Gallimard; Julliard, 1997.

EUROPEAN COMISSION. Eurydice. Recommended annual taught time in full-time compulsory education in Europe 2012-2013. 2013. Disponível em: http://eacea.ec.europa. eu/educataon/eurydice/documents/facts_and_figures/taught_time_EN.pdf. Acesso em: 25 mar. 2015.

Organisation of school time in Europe. Primary and Secondary Education, 2015/2016. 2015. Disponível em: http://eacea.ec.europa.eu/education/eurydice/ documents/facts_and_figures/186EN.pdf. Acesso em: 20 abr. 2015. 
O tempo da escola: organização, ampliação e qualificação do tempo do ensino escolar

FRANCE. Conférence National sur les Rytmmes Scolaries. Rapport de synthèse des auditions, des débats en académie et des échanges sur internet. jan. 2011 . France: Ministères de l'Éducation, Jeunesse et Vie Associative, 2011.

GAUSSEL, Marie. Aux frontières de l'école ou pluralité des temps éducatifs. Dossier d'actualité de la VST, n. 81, jan. 2013. Disponível em: http://ife.ens-lyon.fr/vst/DA-Veille/81janvier-2013.pdf. Acesso em: 18 abr. 2015.

HEIDEGGER, Martin. Ser e tempo. Tradução de Márcia Sá Cavalcante Schubach. 15. ed. Petrópolis: Vozes, 2005.

LECONTE-LAMBERT, Claire. Des rytmes de vie aux rytmes scolaires. Quelle histoire! Villeneuve d'Ascq, France: Presses Universitaires du Septentrion, 2011.

MAULINI, Olivier; PERRENOUD, Philippe. La forme scolaire de l'éducation de base: tensions internes et évolutions. In: MAULINI, Olivier; MONTANDON, Cleopâtre (Dir.). Les formes de I'éducation: varieté et variations. Bruxeles: De Boeck Supérieur, 2005.

NECTA. National Education Commision on Time and Learning. Prisioners of time. Washington: NECTA, 2005.

88 OCDE. Regard

SALDAÑA, Paulo. Escolas de tempo integral do Estado não garantem melhor aprendizado. O Estado de São Paulo, São Paulo, 5 jan. 2013. Disponível em: http://www.estadao.com. $\mathrm{br} /$ noticias/geral, escolas-de-tempo-integral-do-estado-nao-garantem-melhor-aprendizado-imp-, 980380. Acesso em: 12 set. 2015.

SÃO PAULO. Secretaria Estadual de Educação de São Paulo. Resolução SE n 81, de 16 de dezembro de 2011. Estabelece diretrizes para a organização curricular do ensino fundamental e do ensino médio nas escolas estaduais. Disponível em: http://siau.edunet.sp.gov. $\mathrm{br} /$ ItemLise/arquivos/8 1_11.HTM.

TOUITOU, Yvan; BEGUE, Pierre. Aménagement du temps scolaire et santé de l'enfant: vers nouvel horaire scolaire. Académie National de Médicine, Paris, v. 194, n. 1, p. 107-122, 2010 .

WAAUB, Pierre. Le temps d'ensigner. Loverval: Éditons Labor, 2006.

WEBER, Max. Ética protestante e o "espírito" do capitalismo. Tradução de José Marcos Mariani de Macedo. São Paulo: Companhia das Letras, 2004. 
Prof. Dr. Antonio Chizzotti

Pontifícia Universidade Católica de São Paulo

Programa de Pós-Graduação em Educação Grupo de Pesquisa Programa de Estudos Pós-Graduação em Educação: Currículo E-mail | anchizo@uol.com.br

Profa. Dra. Roberta Maria Bueno Bocchi

Pontifícia Universidade Católica de São Paulo Secretaria Estadual de Educação do Estado de São Paulo

Programa de Pós-Graduação em Educação Supervisora de Ensino do Estado de São Paulo Grupo de Pesquisa Programa de Estudos Pós-Graduação em Educação: Currículo E-mail | abocchi@uol.com.br

Recebido 4 out. 2016 Aceito 24 out. 2016 